Research Paper

\title{
Wnt5a Inhibits the Proliferation and Melanogenesis of Melanocytes
}

\author{
Jie Zhang1,2, Yan $\mathrm{Li}^{2}$, Yun $\mathrm{Wu}^{2}$, Tian Yang1, Ke Yang1, Ruimin Wang³, Jin Yang1, Haiying Guo ${ }^{1, \bowtie}$ \\ 1. Department of Cell Biology, Third Military Medical University, Chongqing 400038, China; \\ 2. The Third Military Medical University group 5, Third Military Medical University, Chongqing 400038, China; \\ 3. Department of Cell Biology and Genetics, Chongqing Medical University, Chongqing 400016, China.
}

$\bowtie$ Corresponding author: Tel.: 86-023-68753260; Email: ghy0601@126.com.

(c) Ivyspring International Publisher. This is an open-access article distributed under the terms of the Creative Commons License (http://creativecommons.org/ licenses/by-nc-nd/3.0/). Reproduction is permitted for personal, noncommercial use, provided that the article is in whole, unmodified, and properly cited.

Received: 2012.12.06; Accepted: 2013.03.17; Published: 2013.04.05

\begin{abstract}
Wnt5a, which is a noncanonical Wnt molecule, has been shown to be involved in a variety of developmental processes and cellular functions. In this study, we used "melan-a" cells as a cell model to investigate the effects of Wnt5a on melanocyte proliferation and melanogenesis, and to elucidate the possible mechanisms involved. We infected melan-a cells with recombinant Wnt5a adenoviruses to express $\mathrm{Wnt5}$ a protein and to simulate the $\mathrm{Wnt5}$ a processing environment. MTT assay and BrdU incorporation assay revealed that Wnt5a significantly inhibited the proliferation of melan-a cells. Melanin content and tyrosinase activity assays showed that Wnt5a was an inhibitor of melanin synthesis. Furthermore, RT-PCR and Western blot showed that this suppressive effect depended on noncanonical Wnt/Ror2 pathway activation and accessed the inhibition of the canonical Wnt pathway. The above results provided a novel insight into the role of Wnt5a and its related signaling in melanocyte homeostasis.
\end{abstract}

Key words: Wnt5a; melanocyte; proliferation; melanogenesis; Wnt/Ror2 pathway.

\section{Introduction}

Melanocytes are pigment-producing cells and synthesize melanin that governs skin and hair color and protects individuals from harmful ultraviolet rays $^{1-3}$. Melanocytes produce melanin and transfer them via their dendrite to adjacent keratinocytes. The pigment melanin is well known to protect the skin from harmful UV rays through its optical and chemical filtering properties ${ }^{1,4,5}$. However, over-production and accumulation of melanin due to extreme exposure to UV irradiation or chronic inflammation could lead to various skin disorders, such as melanoma, nevus, freckles and geriatric pigment spots $^{6}$. In mammalian melanocytes, melanin biosynthesis is mainly catalyzed by three melanocyte-specific enzymes: tyrosinase, tyrosinase-related protein-1 (TRP1) and tyrosinase-related protein-2 (TRP2/DCT) ${ }^{4}$. Tyrosinase is the key regulatory enzyme of melanogenesis while TRP1 and TRP2 act as modifiers of melanogenic pathway velocity, and perhaps as regulators of other melanocyte functions ${ }^{4}$.

Wnts are secreted cysteine-rich glycoproteins that participate in cell proliferation, differentiation, and migration ${ }^{7-10}$. To date at least 19 Wnt members have been identified in mammals. Traditionally, the different Wnts have been classified as canonical or noncanonical ${ }^{11}$. In the best characterized canonical pathway, Wnt binding to Frizzled and LRP5/6 co-receptors induces $\beta$-catenin stabilization and translocation to the nucleus where it regulates the transcription of target genes ${ }^{12,13}$. Inversely, the noncanonical pathway is less well defined and its signals are transduced independently of $\beta$-catenin. Noncanonical pathways are diverse and grouped into several categories, such as the planar cell polarity 
pathway (PCP), Wnt/ $\mathrm{Ca}^{2+}$ signaling pathway and Wnt/Ror2 signaling pathway ${ }^{12,13}$.

Previous studies revealed that canonical Wnt signaling, specifically Wnt1 and Wnt3a, has crucial roles in the development of melanocytes ${ }^{14-16}$. Our recent work showed that Wnt3a contributes to promote melanocyte melanogenesis through the upregulation of MITF, tyrosinase and TRP1 17,18. Despite the well-known function of canonical Wnt signaling in melanocytes, the role of noncanonical Wnt signaling in melanocytes remains undetermined. Wnt5a, as a typical noncanonical Wnt member, is essential for cell growth, differentiation and migration. Multiple studies revealed that Wnt5a promotes melanoma tumorigenesis, invasion and metastasis ${ }^{19-21}$. Furthermore, Wnt5a inhibits the expression of melanogenic antigens in melanoma ${ }^{22}$. However, the precise function of Wnt5a in normal melanocytes is unclear yet. Therefore, this study was conducted to investigate the effects of Wnt5a on melanocyte proliferation and melanogenesis, and to elucidate the possible mechanisms involved.

\section{Materials and methods}

\section{I Cell culture}

An immortal line of mouse melanocytes, melan-a, was a kind gift of Dr. D.C. Bennett ${ }^{23}$. The cells were cultured in RPMI 1640 medium (Gibco, USA) supplemented with 10\% FBS (Gibco, USA), $2 \mathrm{mM}$ L-glutamine (Sigma, USA), 200 nM PTA (Sigma, USA), $100 \mathrm{IU} / \mathrm{mL}$ penicillin, $50 \mu \mathrm{g} / \mathrm{mL}$ streptomycin, at $37^{\circ} \mathrm{C}$ under air plus $10 \% \mathrm{CO}_{2}$ conditions.

\subsection{Adenovirus amplification and infection}

The adenoviruses expressing green fluorescent protein (AdGFP), Wnt5a protein (AdWnt5a, also expressing GFP), Wnt3a protein (AdWnt3a, also expressing GFP) were kindly provided by Dr. T.-C. He. The adenoviruses were propagated in HEK 293 cells as described previously ${ }^{24}$. After being purified by caesium chloride gradient centrifugation, adenoviruses were dialyzed into storage buffer, and their titers were determined. For infection, melan-a cells were plated on 6-well or 24-well plates at a density of $2 \times 10^{4}$ cells $/ \mathrm{cm}^{2}$ in the growth medium for $12 \mathrm{~h}$, the cells were then grown in medium supplemented with AdWnt5a or AdGFP, at ultimate titres of $10^{6} \mathrm{PFU} / \mathrm{mL}$.

\subsection{MTT assay}

Melan-a cells were cultured in 96-well plates at an initial density of $5 \times 10^{3}$ cells per well for $12 \mathrm{~h}$, and then treated with Ad-Wnt5a or Ad-GFP. After $48 \mathrm{~h}$, the MTT (Sigma, USA) was added to each well and the cells were incubated at $37^{\circ}$ for $4 \mathrm{~h}$. The medium was removed and dimethyl sulfoxide (DMSO) was added to dissolve the formazan crystals. The absorbance was measured at $490 \mathrm{~nm}$ with an ELISA reader. The experiments were performed in triplicate.

\subsection{BrdU incorporation assay}

Melan-a cells were treated with Ad-GFP or Ad-Wnt5a for $48 \mathrm{~h}$, and then incubated with $10 \mu \mathrm{M}$ BrdU (Sigma, USA) for $4 \mathrm{~h}$. The detection of BrdU was performed as described previously ${ }^{17}$. Briefly, after incubation in HCL and $\mathrm{Na}_{2} \mathrm{~B}_{4} \mathrm{O}_{7}$, the cells were stained with mouse anti-BrdU antibody (Zhongshan, China, 1:100), then incubated with goat anti-mouse Cy3-conjugated secondary antibody (Beyotim, China, 1:300), and finally counterstained with DAPI. Cells were visualized using an upright $\mathrm{BH} 2$ microscope (Olympus, Japan) and quantified by counting BrdU-positive cells in 6 independent areas. The experiments were repeated three times.

\subsection{Melanin content assay}

Melan-a cells were cultured in 6-well plates at a concentration of $1 \times 10^{5}$ cells/well overnight and then infected with AdWnt5a or AdGFP for $48 \mathrm{~h}$. Then the cells were trypsinized and counted. The same number $\left(1 \times 10^{5}\right)$ of cells were collected and the pellets were dissolved in $1 \mathrm{~mL}$ of $1 \mathrm{M} \mathrm{NaOH}$ at $80^{\circ} \mathrm{C}$ for $1 \mathrm{~h}$. Melanin concentrations were measured by absorbance at $405 \mathrm{~nm}$. The experiments were performed at least three times.

\subsection{Tyrosinase activity assay}

Tyrosinase activity assays were performed according to the method previously reported ${ }^{25}$. Melan-a cells in 6-well plates were infected with AdWnt5a or AdGFP for $48 \mathrm{~h}$, then lysed by freezing-thawing cycles in $200 \mu \mathrm{L} 1 \%$ Triton X-100/PBS. The lysates were clarified by centrifugation, $80 \mu \mathrm{L}$ of the supernatant were transferred into 96-well plates and $20 \mu \mathrm{L}$ of 2 $\mathrm{mg} / \mathrm{mL}$ L-Dopa (Sigma, USA) were added. After incubation for $2 \mathrm{~h}$ at $37^{\circ} \mathrm{C}$, absorbance was measured at $490 \mathrm{~nm}$. Total cellular proteins were determined to normalize samples. The measurements were repeated at least three times.

\subsection{Isolation of Total RNA and RT-PCR}

Total RNA was extracted at the indicated time-points using a Trizol Kit (Invitrogen, USA) and reverse-transcribed using a reverse transcription (RT) kit (Toyobo, Japan). Semi-quantitative PCR was performed using primers for Wnt5a, GADPH, $\beta$-catenin, Tyrosinase, TRP1, Ror2, JUN, JNK1 and JNK2 (see Table 1 for primer sequences and amplicon size). PCR reactions were performed using a touchdown proto- 
col previously described ${ }^{26}$. Briefly, touchdown PCR was performed with the following program: 1 cycle at $94^{\circ} \mathrm{C}$ for $2 \mathrm{~min}, 12 \mathrm{cycles}$ at $92^{\circ} \mathrm{C}$ for $20 \mathrm{~s}, 68^{\circ} \mathrm{C}$ for $30 \mathrm{~s}$, and $70^{\circ} \mathrm{C}$ for $45 \mathrm{~s}$ with a decrease of one degree per cycle, and 22 cycles at $92^{\circ} \mathrm{C}$ for $20 \mathrm{~s}, 55^{\circ} \mathrm{C}$ for $30 \mathrm{~s}$, and $70^{\circ} \mathrm{C}$ for $45 \mathrm{~s}$. PCR products were separated by gel electrophoresis in $2 \%$ agarose gels and visualized by ethidium bromide staining.

Table I. The primer sequences for RT-PCR analysis.

\begin{tabular}{|c|c|c|c|}
\hline Primer & & Sequence $\left(5^{\prime}-3^{\prime}\right)$ & $\begin{array}{l}\text { Size } \\
\text { (bp) }\end{array}$ \\
\hline \multirow[t]{2}{*}{ Wnt5a } & Forward & TTGGCCACGTTTTTCTCC & 125 \\
\hline & Reverse & TGGCTGCAGAGAGGCTGT & \\
\hline \multirow[t]{2}{*}{$\beta$-catenin } & Forward & ATCACTGAGCCTGCCATCTG & 581 \\
\hline & Reverse & GTTGCCACGCCTTCATTCC & \\
\hline \multirow[t]{2}{*}{ GAPDH } & Forward & ACCACAGTCCATGCCATCAC & 452 \\
\hline & Reverse & TCCACCACCCTGTTGCTGTA & \\
\hline \multirow{2}{*}{$\begin{array}{l}\text { Tyrosi- } \\
\text { nase }\end{array}$} & Forward & GGGCCCAAATTGTACAGAGA & 174 \\
\hline & Reverse & ATGGGTGTTGACCCATTGTT & \\
\hline \multirow[t]{2}{*}{ TRP1 } & Forward & AAGTTCAATGGCCAGGTCAG & 157 \\
\hline & Reverse & TCAGTGAGGAGAGGCTGGTT & \\
\hline \multirow[t]{2}{*}{ Jun } & Forward & ACTCGGACCTTCTCACGTC & 107 \\
\hline & Reverse & CGGTGTAGTGGTGATGTGCC & \\
\hline \multirow[t]{2}{*}{ JNK1 } & Forward & TCAGAAGCAGAAGCCCCACCA & 211 \\
\hline & Reverse & ACAGACGGCGAAGACGATGGA & \\
\hline \multirow[t]{2}{*}{ JNK2 } & Forward & CCAGCCTTCAGCACAGATGCAG & 295 \\
\hline & Reverse & TGAGCAGGGCAAGGCATCGT & \\
\hline \multirow[t]{2}{*}{ Ror2 } & Forward & CCACTGGGGTTCTATATG TGCG & 138 \\
\hline & Reverse & AAATAGTCCGGTTCCCAATGAAG & \\
\hline
\end{tabular}

\subsection{Western blot analysis}

Whole protein was extracted in RIPA lysis buffer (Beyontime, China), determined by the BCA Protein Assay Kit (Beyontime, China), denatured by boiling, and subjected to $10 \%$ SDS-PAGE. Then the protein was transferred onto a PVDF membrane. After blocked with $5 \%$ fat-free milk, the membranes were probed with rabbit anti-Wnt5a antibody (1:200, R\&D, USA), goat anti-TRP1 antibody (1:1000, Santa Cruz, USA), goat anti-tyrosinase antibody (1:1000, Santa Cruz, USA) at $4^{\circ} \mathrm{C}$ overnight. Blots were then incubated with HRP-conjugated secondary antibody for 1 h. Proteins of interest were visualized on X-ray film by means of the ECL western blot detection system.

\subsection{Subcutaneous implantation and Fon- tana-Masson melanin staining}

Melan-a cells were infected with AdGFP or AdWnt5a for $36 \mathrm{~h}$, and collected for subcutaneous injection ( $10^{6}$ cells/injection) into the back of athymic nude (nu/nu) mice (4-6 wk). Animals were sacrificed 3 days later. Implanted sites were removed and fixed in $4 \%$ paraform. Paraffin sections were processed, and melanin granules were coloured with Fontana-Masson staining, cell nuclei were counterstained with hematoxylin.

\subsection{Statistical analysis}

Data are presented as mean \pm SD of three independent experiments. Statistical analysis between groups was performed by ANOVA using SPSS 18.0. $p$ $<0.05$ was considered to be statistically significant.

\section{Results}

\section{I Wnt5a inhibits the proliferation of melan-a cells}

To explore the possible role of Wnt5a in melanocytes, we used mouse melanocyte line (melan-a) as an in vitro cell model and infected the cells with AdWnt5a to serve as the production source of Wnt5a protein. The adenovirus infection efficiency was examined by green fluorescence (Fig. $1 \mathrm{~A}$ ) and the expression of Wnt5a was confirmed by RT-PCR and Western Blot (Fig.1 B).

To determine the effect of Wnt5a on the proliferation of melan-a cells, we infected melan-a cells with different doses of AdWnt5a or AdGFP as control. After 48 hours, the MTT assay showed that Wnt5a inhibited the proliferation of melan-a cells in a dose-dependent manner compared to GFP (Fig. 1 C). Similarly, the BrdU incorporation assay indicated the ratio of proliferating AdWnt5a-infected cells was lower than that in controls ( $p<0.05)$ (Fig.1 D). The results implied that Wnt5a inhibited the proliferation of melan-a cells.

\subsection{Wnt5a inhibited the melanogenesis of melan-a cells}

Since tyrosinase is the key regulatory enzyme for melanin synthesis, its activity is a marker for melanocyte melanogenesis. As shown in Figure 2 A, Wnt5a inhibited the tyrosinase activity of melan-a cells in a dose-dependent manner compared to GFP ( $p<0.05$ ). In conformity with the results of the tyrosinase activity assay, AdWnt5a-infected cells decreased melanin synthesis significantly compared to AdGFP-infected cells $(\mathrm{p}<0.05)$ (Fig. 2 B).

To investigate how Wnt5a inhibits melanin synthesis, we analyzed the expression levels of the melanogenic enzymes, tyrosinase and TRP1. A great significant decrease of tyrosinase and TRP1 mRNA were detected in AdWnt5a-infected cells rather than control 
especially at 48 hours (Fig. 2 C). Western blot analyses also showed that Wnt5a did remarkably decrease the protein levels of tyrosinase and TRP1 (Fig. 2 D). And subcutaneous implantation experiments verified that Wnt5a inhibited melanin synthesis in vivo (Fig. 2 E).

\subsection{Wnt5a activated the Wnt/Ror2 signaling pathway in melan-a cells}

Since Wnt5a may activate the noncanonical pathway via the Wnt/Ror2 signaling pathway ${ }^{27}$, we first determined if Wnt5a stimulated Wnt/Ror2 signaling pathway member mRNA expression levels in melan-a cells by RT-PCR. Our analyses showed that Wnt5a increased the expression levels of Ror2, c-JUN, JNK1 and JNK2 in a time-dependent manner. The mRNA levels reached a peak at $24 \mathrm{~h}$ and then recovered by $48 \mathrm{~h}$ (Fig. 3). The results suggested that Wnt5a might activate Wnt/Ror2 signaling pathway in melan-a cells.
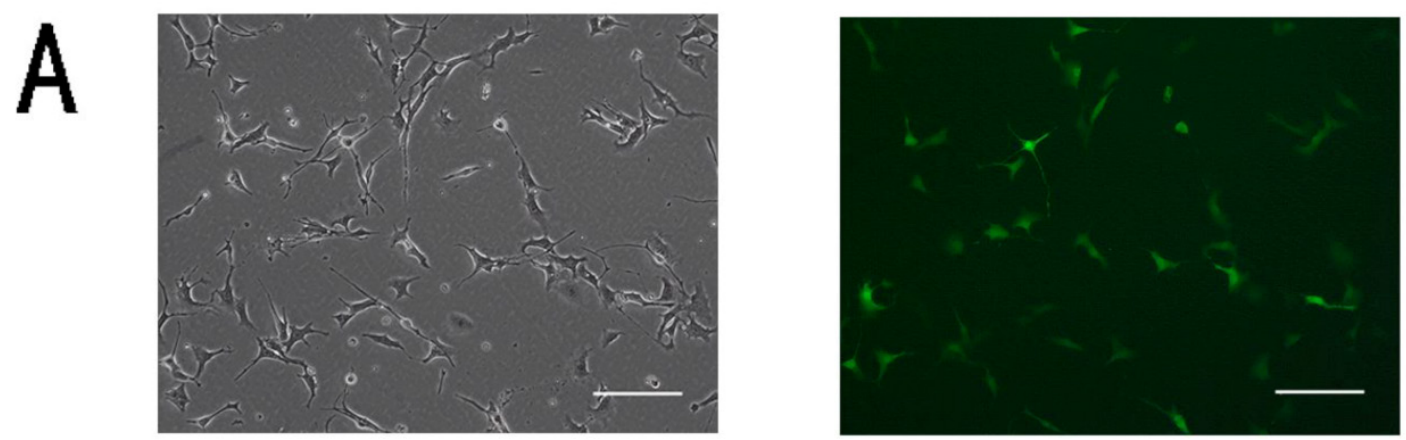

B

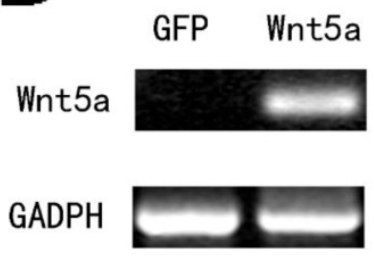

RT-PCR

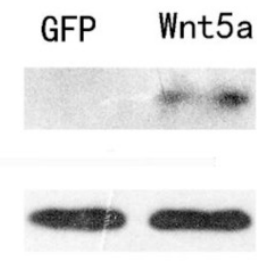

Western blot
Q

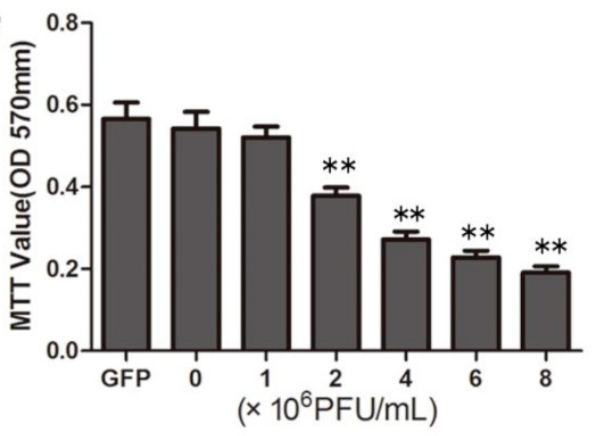

D

BrdU

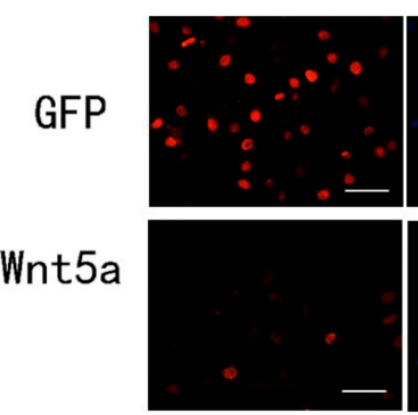

DAPI
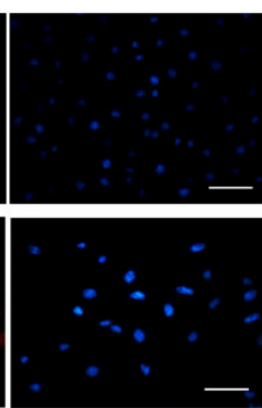

\section{Merge}
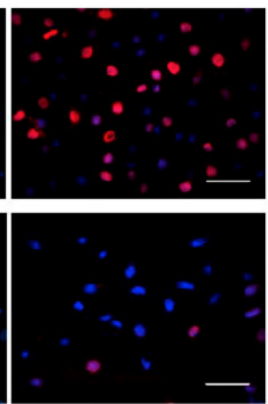

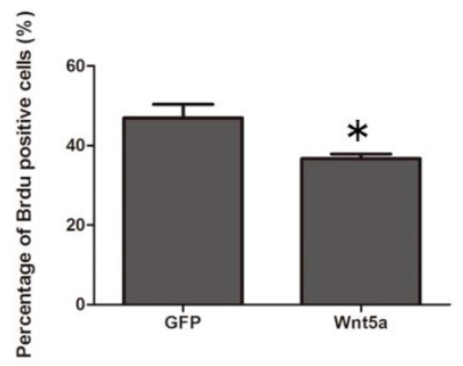

Fig I. Effects of Wnt5a on the proliferation of melan-a cells. (A) Melan-a cells infected by Ad-Wnt5a. The infection efficiency was observed by green fluorescence. (Left, phase contrast images; Right, fluorescent images) Scale bars represent $100 \mu m$. (B) RT-PCR and Western-blot analysis of Wnt5a mRNA and protein after infection with AdWnt5a or AdGFP. (C) Proliferation of melan-a cells infected with different doses of AdWnt5a or AdGFP as measured by the MTT assay. (D) Proliferation of melan-a cells infected with AdGFP or AdWnt5a as measured by BrdU incorporation. BrdU incorporation was detected by immunofluorescent staining (Left), and the percentage of BrdU positive cells were quantitatively measured (Right). Red, BrdU; Blue, DAPI. Scale bars represent $50 \mu \mathrm{m} .{ }^{*} \mathrm{p}<0.05,{ }^{* *} \mathrm{p}<0.01 . \mathrm{n}=3$. 

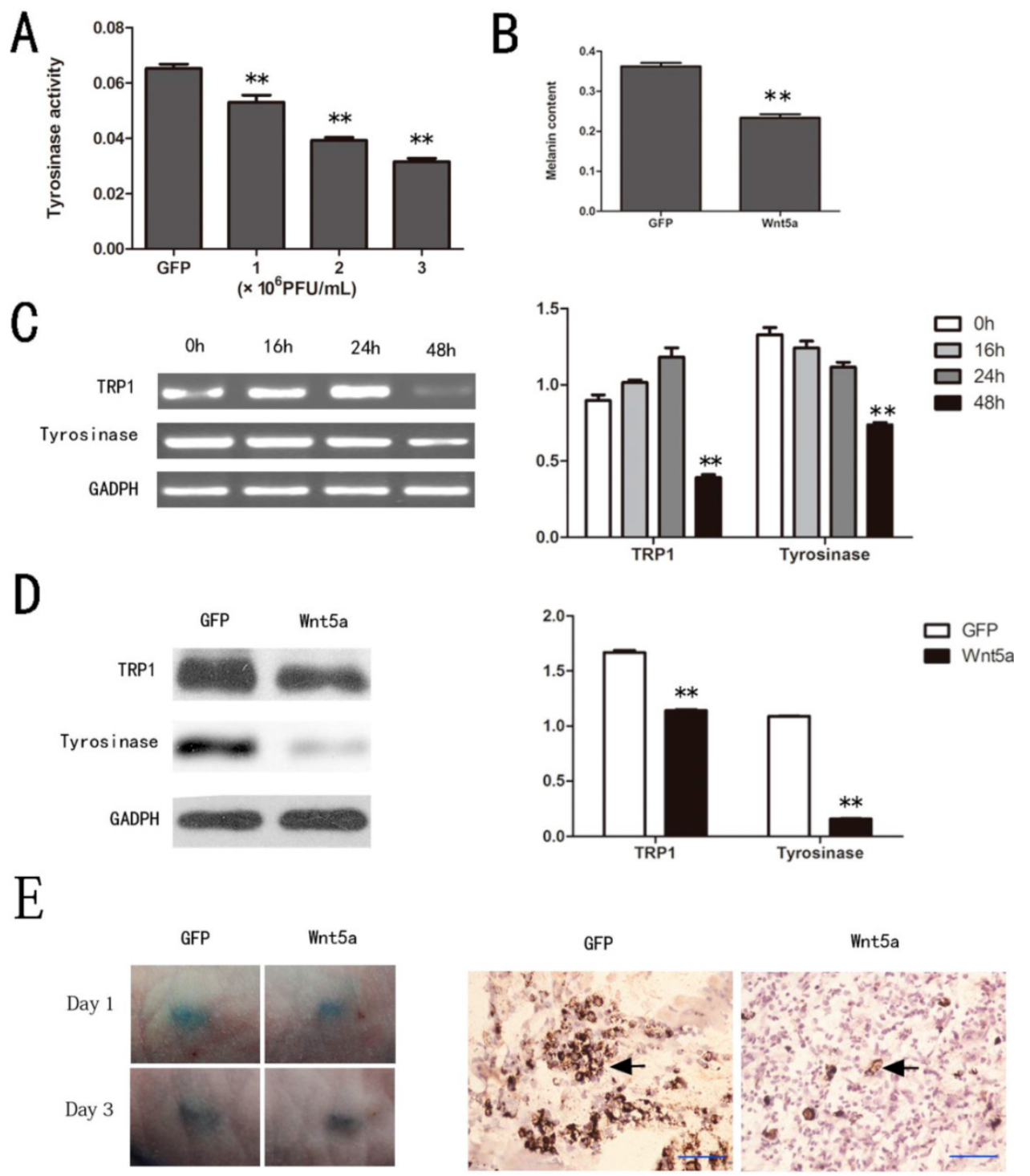

Fig 2. Effects of Wnt5a on the melanogenesis of melan-a cells. (A) Tyrosinase activity of melan-a cells infected with different doses of AdWnt5a or AdGFP analyzed by tyrosinase activity assay. (B) Melanin synthesis of melan-a cells infected with AdWnt5a or AdGFP. (C-D) Effect of Wnt5a on the expression of TRPI and tyrosinase in melan-a cells. (C) Melan-a cells were infected with AdWnt5a or AdGFP. RT-PCR analyses were performed with primers specific for TRPI, tyrosinase and GADPH after 0h, 16h, 24h and 48h. (D) Melan-a cells were infected with AdWnt5a or AdGFP. After $48 \mathrm{~h}$, Western blot analyses were performed with antibodies specific for TRPI, tyrosinase and GADPH. (E) Melan-a cells infected with AdWnt5a or AdGFP were implanted subcutaneously into nude mice. Visual pigmentation were exhibited in Day I and 3. Implanted sites were retrieved and subjected to Fontana-Masson staining. Melanin-positive cells were indicated with arrows. Bar $=50 \mu \mathrm{m}$. These data were representative results of three independent experiments. ${ }^{*} p<0.05$, ${ }^{* *} \mathrm{p}<0.01$.

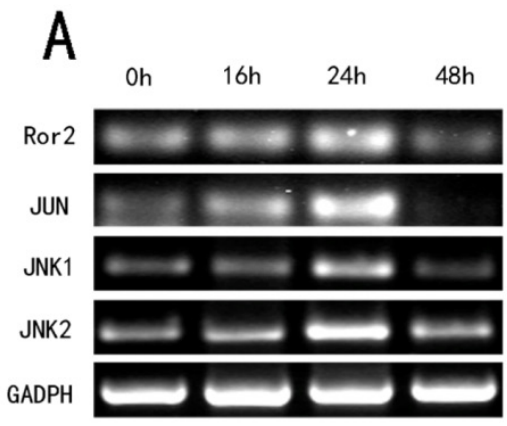

B

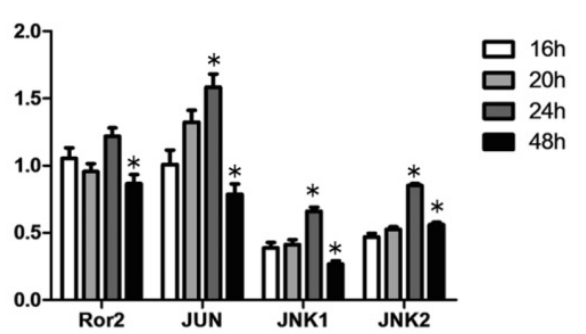

Fig 3. Effects of Wnt5a on the Wnt/Ror2 signalling pathway in melan-a cells. (A) Melan-a cells were infected with AdWnt5a. After $0 \mathrm{~h}$, I6h, 24h and 48h, RT-PCR analyses were performed with primers specific for Ror2, JUN, JNKI, JNK2 and GADPH. (B) The relative mRNA expression levels. These data were representative results of three independent experiments. ${ }^{*} p<0.05$. 
A

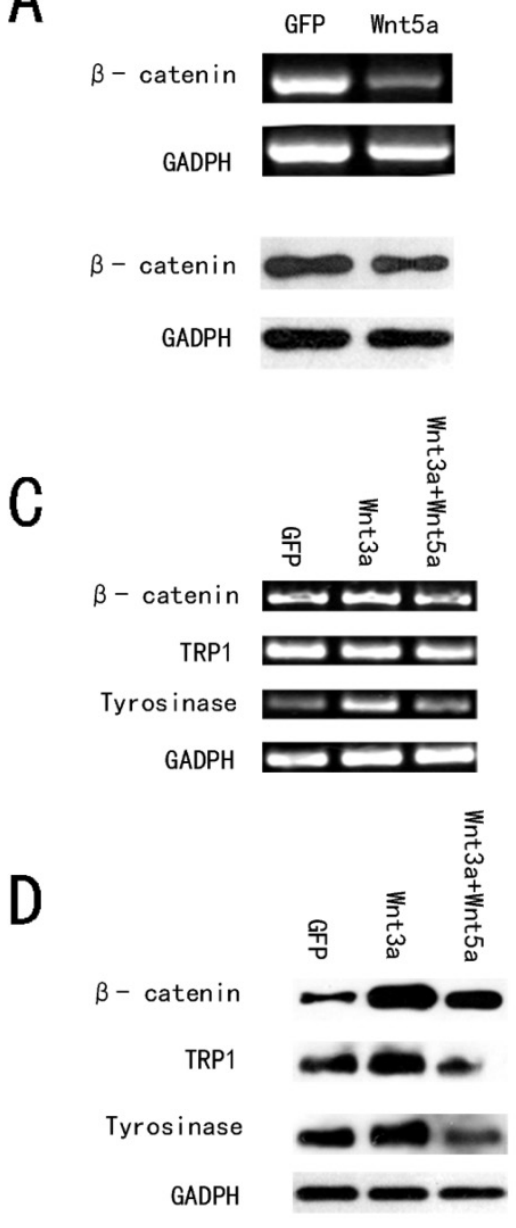

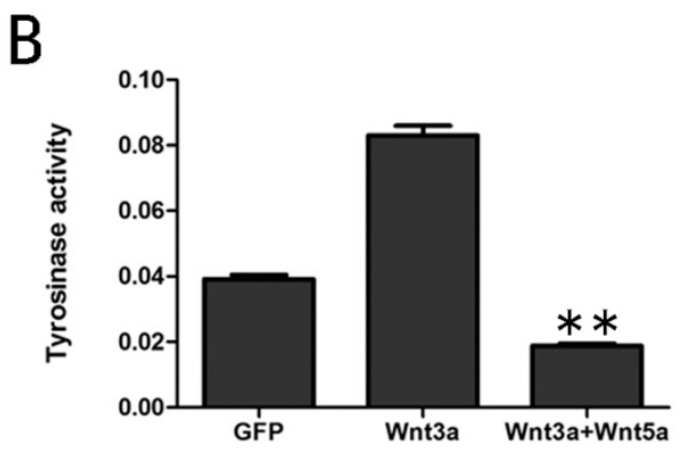
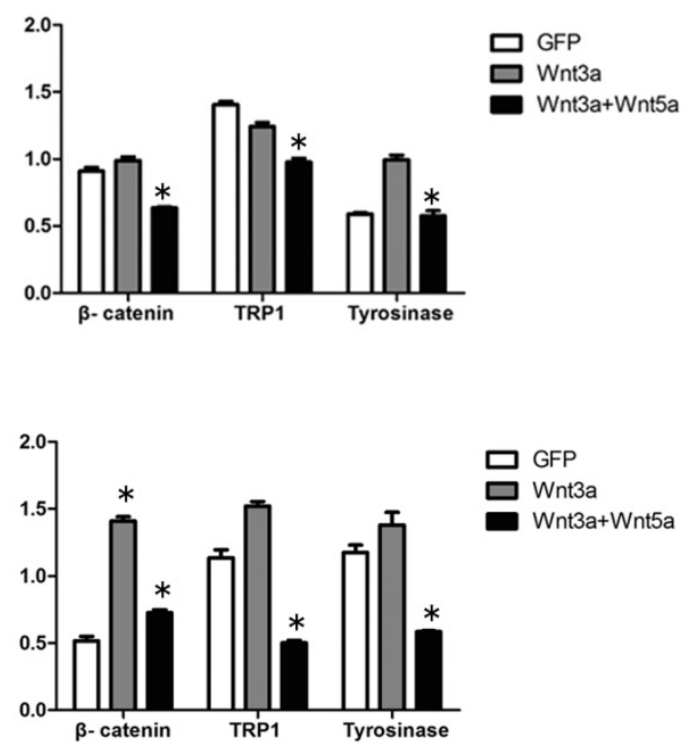

Fig 4. Effects of Wnt5a on the canonical Wnt signalling pathway in melan-a cells. (A) Effect of Wnt5a on the expression of $\beta$-catenin mRNA and protein as measured by RT-PCR and Western blot assays. (B) Effect of Wnt5a on the tyrosinase activity in AdWnt3a-infected melan-a cells. The cells were infected with AdGFP, AdWnt3a, or co-infected with AdWnt3a and AdWnt5a. After $48 \mathrm{~h}$, tyrosinase activity was analyzed by tyrosinase activity assay. (C-D) Effect of Wnt5a on the expression of $\beta$-catenin, TRPI and tyrosinase in AdWnt3a-infected melan-a cells. The cells were infected with AdGFP, AdWnt3a, or co-infected with AdWnt3a and AdWnt5a for $48 \mathrm{~h}$. (C) RT-PCR analyses were performed with primers specific for $\beta$-catenin, TRPI, tyrosinase and GADPH (Left) and the relative mRNA expression levels were quantitatively measured (Right). (D) Western blot analyses were performed with antibodies specific for $\beta$-catenin, TRPI, tyrosinase and GADPH (Left) and the relative protein expression levels were quantitatively measured (Right). These data were representative results of three independent experiments. ${ }^{*} p<0.05$.

\subsection{Wnt5a antagonized canonical Wnt signal- ing pathway in melan-a cells}

It has been reported that Wnt5a/Ror2 signaling also antagonized the canonical Wnt signaling pathway $27-28$, so we tested the expression level of $\beta$-catenin in AdWnt5a-infected cells. Both RT-PCR and Western blot analyses showed that Wnt5a significantly decreased the expression level of $\beta$-catenin in melan-a cells (Fig. 4 A).

To further examine the function of Wnt5a in canonical Wnt signaling pathway in melan-a cells, we infected the cells with AdGFP, AdWnt3a, or co-infected with AdWnt3a and AdWnt5a. We tested the expression level of $\beta$-catenin, as shown in Figure 4 $\mathrm{C}$ and D. A significant decrease in $\beta$-catenin protein levels was detected in co-infected cells compared with AdWnt3a-infected cells, suggested that Wnt5a could antagonize the canonical Wnt signaling pathway by reversing $\beta$-catenin expression driven by Wnt3a. The tyrosinase activity assay revealed that Wnt3a increased the tyrosinase activity and Wnt5a remarkably reversed the tyrosinase activity induced by Wnt3a (Fig. 4 B). We then studied the expression of tyrosinase and TRP1 in co-infected cells compared with AdWnt3a-infected cells. RT-PCR and Western blot analyses each showed that Wnt5a down-regulated the expression levels of these pigmentation-related mRNAs and proteins upregulated by Wnt3a (Fig. 4 C and D).

These results suggested that Wnt5a antagonized the canonical Wnt signaling pathway in melan-a cells. 


\section{Discussion}

Wnt signaling plays an important role in essential developmental processes such as proliferation, migration, and differentiation ${ }^{29-31}$. As a representative noncanonical molecule, Wnt5a has been studied especially in melanoma ${ }^{32-34}$ but its role in normal melanocytes is not clearly understood.

In order to investigate the possible function of Wnt5a in melanocytes, we introduced the "melan-a" cell line which was derived from normal epidermal melanoblasts of C57BL mice ${ }^{23}$. In this study, we infected melan-a cells with AdWnt5a and verified that Wnt5a protein was efficiently expressed. Therefore we used melan-a cells infected with recombinant adenoviruses as an in vitro cell model to explore the effect of Wnt5a in melanocytes.

Wnts control various cellular functions, including proliferation. Previous studies showed that Wnt5a inhibited the proliferation of human dental papilla cells, human endothelial cells, and B cells $\mathrm{s}^{8,35,36}$. In th is study, MTT and BrdU incorporation assays showed that Wnt5a also suppressed the proliferation of melan-a cells.

Then we investigated the influence of Wnt5a on the melanogenesis of melanocytes. The melanin content assay and Tyrosinase activity assay both indicated that Wnt5a inhibited melanogenesis in melan-a cells. RT-PCR and Western blot analyses revealed that Wnt5a down-regulated the expression level of the pigment cell-specific genes, including tyrosinase and TRP1 in melan-a cells. Our results suggested that Wnt5a inhibited melanin synthesis through the down-regulation of pigment cell-specific genes in melanocytes.

The noncanonical Wnt signaling pathway is often referred to as $\beta$-catenin-independent and can be divided into several categories, such as PCP, Wnt/ $\mathrm{Ca}^{2+}$ and Wnt/Ror2 signaling pathways ${ }^{27}$. To clarify which pathway Wnt5a induced in melanocytes, we detected RhoA, Dvl and Ror2, which are classical molecules in PCP, Wnt/ $\mathrm{Ca}^{2+}$ and Wnt/Ror2 signaling pathways, respectively ${ }^{27}$. In contrast to increasing Ror2 pathway expression in AdWnt5a-infected cells, RhoA and Dvl remained unchanged (data not shown). The receptor tyrosine kinase Ror2 has been shown to act as a receptor or coreceptor for Wnt5a to mediate Wnt5a-induced activation of the Wnt/JNK pathway and inhibition of the $\beta$-catenin-dependent canonical Wnt pathway ${ }^{37-39}$. So we focused on the Wnt/Ror2 signaling pathway in this project. We detected the expression of JNK1, JNK2 and c-JUN and revealed that Wnt5a could transiently increase expression of these 3 mRNAs in a short time (in the $24 \mathrm{~h}$ after AdWnt5a infection) and revert back to baseline levels by $48 \mathrm{~h}$. Our data are consistent with the result of Nomachi A. et al. that Wnt5a induces the activation of JNK in a Ror2-dependent manner ${ }^{37}$.

Our laboratory has recently shown that Wnt3a, a typical canonical Wnt pathway molecule, promoted melanogenesis of melanocytes via the up-regulation of the expression of MITF, tyrosinase and TRP1 17,18 . Since Wnt5a generally functions by antagonizing the canonical Wnt signaling pathway ${ }^{40}$, we tested whether Wnt5a might inhibit melanin synthesis by suppressing the Wnt3a mediated canonical signaling pathway. Since $\beta$-catenin is the key downstream mediator of canonical Wnt signaling, we examined $\beta$-catenin expression levels when melan-a cells were infected with AdWnt3a or co-infected with AdWnt5a and AdWnt3a. The results were consistent with our previous observation that Wnt3a activated canonical Wnt signaling by up-regulating $\beta$-catenin expression ${ }^{17}$ and, Wnt5a reversed this response. In support of our findings, Topol L. et al. have reported that Wnt5a antagonized the canonical Wnt pathway by promoting the degradation of $\beta$-catenin ${ }^{40}$. To investigate the effect of Wnt5a on melanin synthesis stimulated by Wnt3a signaling, we analyzed the expression of tyrosinase and TRP1 in co-infected cells compared with AdWnt3a-infected cells. The data revealed that Wnt5a inhibited the expression of tyrosinase and TRP1 enhanced by Wnt3a suggesting that Wnt5a could inhibit melanin synthesis by suppressing canonical Wnt signaling in melanocytes.

In summary, we demonstrate that Wnt5a can activate Wnt/Ror2 signaling and suppress canonical Wnt signaling and thereby inhibit the proliferation and melanin synthesis of melan-a cells.

\section{Acknowledgements}

This work was supported by the National Natural Science Foundation of China (No. 81071309). We thank Dr. T-C. He (Chicago University) for adenovirus production. We thank Prof. Dorothy $\mathrm{C}$ Bennett (University of London) and Dr. Zhixiu Lin (The Chinese University of Hong Kong) for providing melan-a cells and helpful advice. We are also grateful to Dr. Randall Widelitz (University of Southern California) for carefully revising the manuscript.

\section{Abbreviations}

Ad: adenovirus; MITF: microphthalmia-associated transcription factor; TRP1: tyrosinase-related protein 1; TRP2: tyrosinase-related protein 2; TPA: 12-o-tetradecanoyl phorbol-13-acetate. 


\section{Competing Interests}

The authors have declared that no competing interest exists.

\section{References}

1. Park HY, Kosmadaki M, Yaar M, Gilchrest BA. Cellular mechanisms regulating human melanogenesis. Cell Mol Life Sci. 2009;66:1493-506.

2. Thomas AJ, Erickson CA. The making of a melanocyte: the specification of melanoblasts from the neural crest. Pigment Cell Melanoma Res. 2008;21:598-610.

3. Nishimura EK. Melanocyte stem cells: a melanocyte reservoir in hair follicles for hair and skin pigmentation. Pigment Cell Melanoma Res. 2011; 24:401-10.

4. Slominski A, Tobin DJ, Shibahara S, Wortsman J. Melanin pigmentation in mammalian skin and its hormonal regulation. Physiol Rev. 2004;84:1155-228.

5. Yamaguchi $\mathrm{Y}$, Brenner M, Hearing VJ. The regulation of skin pigmentation. J Biol Chem. 2007;282:27557-61.

6. Passeron T, Mantoux F, Ortonne JP. Genetic disorders of pigmentation. Clin Dermatol. 2005;23:56-67.

7. Willert K, Brown JD, Danenberg E, et al. Wnt proteins are lipid-modified and can act as stem cell growth factors. Nature. 2003;423:448-52.

8. Peng L, Ye L, Dong G, et al. WNT5A inhibits human dental papilla cell proliferation and migration. Biochem Biophys Res Commun. 2009;390:1072-8.

9. Valencia J, Hernandez-Lopez C, Martinez VG, et al. Wnt5a Skews Dendritic Cell Differentiation to an Unconventional Phenotype with Tolerogenic Features. Journal of Immunology. 2011;187:4129-39.

10. Yamagata K, Li X, Oneyama C, et al. Dissection of Wnt5a-Ror2 Signaling Leading to Matrix Metalloproteinase (MMP-13) Expression. Journal of Biological Chemistry. 2012;287:1588-99.

11. Kikuchi A, Yamamoto H, Kishida S. Multiplicity of the interactions of Wnt proteins and their receptors. Cell Signal. 2007;19:659-71.

12. Eisenmann DM. Wnt signaling. WormBook. 2005;:1-17.

13. Miller JR. The Wnts. Genome Biol. 2002;3:3001.

14. Dorsky RI, Moon RT, Raible DW. Control of neural crest cell fate by the Wnt signalling pathway. Nature. 1998;396:370-3.

15. Dunn KJ, Brady M, Ochsenbauer-Jambor C, Snyder S, Incao A, pavan WJ. WNT1 and WNT3a promote expansion of melanocytes through distinct modes of action. Pigment Cell Research. 2005;18:167-80.

16. Ikeya M, Lee SM, Johnson JE, McMahon AP, Takada S. Wnt signalling required for expansion of neural crest and CNS progenitors. Nature. 1997;389:966-70.

17. Guo H, Yang K, Deng F, et al. Wnt3a inhibits proliferation but promotes melanogenesis of melan-a cells. Int J Mol Med. 2012;30:636-42.

18. Guo H, Yang K, Deng F, et al. Wnt3a promotes melanin synthesis of mouse hair follicle melanocytes. Biochem Biophys Res Commun. 2012;420:799-804.

19. Weeraratna AT, Jiang $Y$, Hostetter $G$, et al. Wnt5a signaling directly affects cell motility and invasion of metastatic melanoma. Cancer Cell. 2002;1:279-88.

20. Bachmann IM, Straume O, Puntervoll HE, Kalvenes MB, Akslen LA. Importance of P-cadherin, beta-catenin, and Wnt5a/frizzled for progression of melanocytic tumors and prognosis in cutaneous melanoma. Clin Cancer Res. 2005;11:8606-14.

21. Da Forno PD, Prinqle JH, Hutchinson P, et al. WNT5A expression increases during melanoma progression and correlates with outcome. Clin Cancer Res. 2008; 14:5825-32.

22. Dissanayake SK, Olkhanud PB, O'Connell MP, et al. Wnt5A regulates expression of tumor-associated antigens in melanoma via changes in signal transducers and activators of transcription 3 phosphorylation. Cancer Res. 2008;68:10205-14.

23. Bennett DC, Cooper PJ, Hart IR. A line of non-tumorigenic mouse melanocytes, syngeneic with the B16 melanoma and requiring a tumour promoter for growth. Int J Cancer. 1987;39:414-8.

24. Luo J, Deng ZL, Luo X, et al. A protocol for rapid generation of recombinant adenoviruses using the AdEasy system. Nature Protocols. 2007;2:1236-47.

25. Bellei B, Maresca V, Flori E, Pitisci A, Larue L, Picardo M. p38 regulates pigmentation via proteasomal degradation of tyrosinase. J Biol Chem. 2010;285:7288-99.

26. Peng Y, Kang Q, Cheng H, et al. Transcriptional characterization of bone morphogenetic proteins (BMPs)-mediated osteogenic signaling. J Cell Biochem. 2003;90:1149-65.
27. Semenov MV, Habas R, Macdonald BT, He X. SnapShot: Noncanonical Wnt Signaling Pathways. Cell. 2007;131:1378.

28. Nishita M, Itsukushima S, Nomachi A, et al. Ror2/Frizzled complex mediates Wnt5a-induced AP-1 activation by regulating Dishevelled polymerization. Mol Cell Biol. 2010;30:3610-9.

29. Reya T, Clevers H. Wnt signalling in stem cells and cancer. Nature. 2005;434:843-50.

30. Kikuchi A, Kishida S, Yamamoto H. Regulation of Wnt signaling by protein-protein interaction and post-translational modifications. Experimental and Molecular Medicine. 2006;38:1-10.

31. Weeraratna AT, Jiang $Y$, Hostetter $G$, et al. Wnt5a signaling directly affects cell motility and invasion of metastatic melanoma. Cancer Cell. 2002;1:279-88.

32. Jenei V, Sherwood V, Howlin J, et al. A t-butyloxycarbonyl-modified Wnt5a-derived hexapeptide functions as a potent antagonist of Wnt5a-dependent melanoma cell invasion. Proc Natl Acad Sci U S A. 2009;106:19473-8.

33. O'Connell MP, Fiori JL, Xu M, et al. The orphan tyrosine kinase receptor, ROR2, mediates Wnt5A signaling in metastatic melanoma. Oncogene. 2010; 29:34-44.

34. O'Connell MP, Fiori JL, Bauqher KM, et al. Wnt5A Activates the Calpain-Mediated Cleavage of Filamin A. Journal of Investigative Dermatology. 2009;129:1782-9.

35. Liang HL, Chen $\mathrm{Q}$, Coles $\mathrm{AH}$, et al. Wnt5a inhibits B cell proliferation and functions as a tumor suppressor in hematopoietic tissue. Cancer Cell. 2003;4:349-60.

36. Cheng CW, Yeh JC, Fan TP, Smith SK, Charnock-Jones DS. Wnt5a-mediated non-canonical Wnt signalling regulates human endothelial cell proliferation and migration. Biochem Biophys Res Commun. 2008;365:285-90.

37. Nomachi A, Nishita M, Inaba D, Enomoto M, Hamasaki M, Mianmi Y. Receptor tyrosine kinase Ror2 mediates Wnt5a-induced polarized cell migration by activating c-Jun N-terminal kinase via actin-binding protein filamin A. Journal of Biological Chemistry. 2008;283:27973-81.

38. Yuan Y, Niu CC, Deng G, et al. The Wnt5a/Ror2 noncanonical signaling pathway inhibits canonical Wnt signaling in K562 cells. Int J Mol Med. 2011;27:63-9.

39. Schambony A, Wedlich D. Wnt-5A/Ror2 regulate expression of XPAPC through an alternative noncanonical signaling pathway. Developmental Cell. 2007;12:779-92.

40. Topol L, Jiang X, Choi H, Garrett-Beal L, Carolan PJ, Yang Y. Wnt-5a inhibits the canonical Wnt pathway by promoting GSK-3-independent beta-catenin degradation. J Cell Biol. 2003;162:899-908. 